Journal of Engineering and Applied Sciences 14 (14): 4838-4841, 2019

ISSN: 1816-949X

(C) Medwell Journals, 2019

\title{
The Cosine and Sine Transform of Fourier
}

\author{
Andrey Valerianovich Pavlov \\ Department of Higher Mathematics-1, MIREA MTU, Mascow, Russia
}

\begin{abstract}
It is proved in study, the transform of Laplace from the transform of Fourier do not have an complex part on the complex axis in different situations. For proof the decision of the Dirichlet problem in semi-plane was used. From the fact, we obtain for the wide class of function that it is possible to change by places a cosine and sine transform of Fourier on the positive axis and that the cosine and asine transform of Fourier are equal on the module.
\end{abstract}

Key words: Transform of Laplace, transform of Fourier, transposition of sine and cosine transform of Fourier, equality of the cosine transform with the sine transform of Fourier, function, complex

\section{INTRODUCTION}

It is proved that it is possible to change by places a cosine and sine transform of Fourier. The fact is the basic result of the study (the remark 1 ). From the fact we obtain that the cosine and sine transform of Fourier are equal on the module. All the transform of Fourier are considered on the positive axis (Pavlov-Maxorin, 2018; Pavlov, 2017):

If:

$$
\left|\mathrm{C}^{0} \mathrm{u}(\mathrm{t})(\cdot)(\mathrm{x})\right|=\left|\mathrm{S}^{0} \mathrm{u}(\mathrm{t})(\cdot)(\mathrm{x})\right|, \mathrm{x} \in[0,+\infty)
$$

$$
\begin{aligned}
& C^{0} u(x)(\cdot)(y)=\int_{0}^{\infty} \cos x y u(x) d x \\
& S^{0} u(x)(\cdot)(y)=\int_{0}^{\infty} \sin x y u(x) d x, y \in[0, \infty)
\end{aligned}
$$

For wide class of the $\mathrm{u}(\mathrm{x})$ functions (the remark 2 ). In the study, the same denotations are used as in the studies (Pavlov-Maxorin, 2018; Pavlov, 2016, 2017):

$$
\begin{aligned}
& \mathrm{L}_{ \pm} \mathrm{S}(\mathrm{x})(\cdot)(v)=\int_{0}^{\infty} \mathrm{e}^{ \pm v \mathrm{x}} \mathrm{S}(\mathrm{x}) \mathrm{dx}, v \in[0, \infty) \\
& \mathrm{L}_{-} \equiv \mathrm{L} \\
& \mathrm{F}_{ \pm} \mathrm{u}(\mathrm{x})(\cdot)(\mathrm{y})=\int_{-\infty}^{\infty} \mathrm{e}^{\mathrm{tixy}} \mathrm{u}(\mathrm{x}) \mathrm{dx} \\
& \mathrm{y} \in(-\infty, \infty)
\end{aligned}
$$

From point of further applications the theorem 1 is the main part of study. It is proved in the theorem 1 that:

$$
\operatorname{ImLF} \mathrm{u}(\mathrm{x})(\cdot)(\text { is }) \equiv 0, \mathrm{~s} \in[0, \infty)
$$

For wide class of the $\mathrm{u}(\mathrm{x})$ functions (Pavlov-Maxorin 2018; Pavlov, 2016, 2017). From the result in future, it is possible to get a inverse equation of the $\operatorname{LS}(x)().(v)$ transform with help only the $v \in[0, \infty)$ values. With the point of view of researcher the theorem 1 requires in future the detailed analysis in the direction of concordance of the results with the before known, foremost in the direction of physical applications for instance in the mathematical models of distribution of plasma in connection with the Dirichlet problem (in the study the themes are not considered).

The result of the study with the same theme (Pavlov, 2016) (only for the $\mathrm{u}(-\mathrm{x})=\mathrm{u}(\mathrm{x})$ functions) ensues from the fact the transform of Laplace do not have an complex part on the complex axis in different situations. We will mark that the proof of the theorem 1 (Pavlov, 2017; Pavlov-Maxorin, 2018) is unconnected with the results of the (Pavlov, 2016) study and the proof of the theorem 1 is conducted by the elementary methods in the substantially more general situation than in the study (Pavlov, 2016). The application of the Dirichlet problem (in the theorem 1) to research of the sine and cosine transform of Fourier first appeared in the researches of Pavlov-Maxorin (2018) and Pavlov (2017).

\section{MATERIALS AND METHODS}

The cosine and sine transform of Fourier: The basic result of the part is formulated in the theorem 1. The remark 1 follows at first from the analytical expression of the complex part of the theorem 1, secondly, from the results of the study (Pavlov, 2016) in the study the complex part of $\mathrm{LF}_{+} \mathrm{u}(\mathrm{x})($ ) (is) in the form of potential is resulted. If as the $\mathrm{u}(\mathrm{x})$ function in $\mathrm{LF}_{+} \mathrm{u}(\mathrm{x})($.) (-is) to consider the: 


$$
\mathrm{C}^{0} \mathrm{u}(\mathrm{t})(\cdot)(\mathrm{x})+\mathrm{S}^{0} \mathrm{u}(\mathrm{t})(\cdot)(\mathrm{x})
$$

sum, we get the remark 2. We use the Y1 condition.

The $Y 1$ condition: The $Y 1$ condition takes place if the:

$$
\mathrm{u}(\mathrm{x}), \mathrm{du}(\mathrm{x}) / \mathrm{dx}, \mathrm{d}^{2} \mathrm{u}(\mathrm{x}) / \mathrm{dx}^{2}
$$

Functions are continuous for all:

$$
\begin{aligned}
& x \in(-\infty, 0) \bigcap[0,+\infty) \\
& d^{2} u(x+0) / d x^{2}=d^{2} u(x) / d x^{2} \\
& d u(x+0) / d x=d u(x) / d x, u(x+0)=u(x) \\
& d^{2} u(x-0) / d x^{2}=A_{2}, d u(x-0) / d x=A_{1} \\
& u(x-0)=A_{3} \\
& A_{1}, A_{2}, A_{3}=\text { const } \\
& A_{1}<\infty, A_{2}<\infty, A_{3}<\infty, u(0)=0
\end{aligned}
$$

And:

$$
\begin{aligned}
& |\mathrm{u}(\mathrm{x}) \| \mathrm{x}|^{\beta+\delta} \rightarrow 0,|\mathrm{x}| \rightarrow \infty, \delta>0, \mathrm{x} \in(-\infty, \infty) \\
& \operatorname{Imu}(\mathrm{s}) \equiv 0, \mathrm{~s} \in(-\infty, \infty)
\end{aligned}
$$

\section{RESULTS AND DISCUSSION}

\section{Theorem 1:}

$$
\operatorname{ImLF}_{+} \mathrm{u}(\mathrm{x})(\cdot)(\mathrm{is}) \equiv 0, \mathrm{~s} \in(-\infty, \infty)
$$

If for the $\mathrm{u}(\mathrm{x})$ function the $\mathrm{Y} 1$ condition takes place.

Proof: From the:

$$
\begin{aligned}
& \mathrm{L}(\mathrm{s})=\mathrm{L}_{+} \mathrm{F}_{-} \mathrm{u}(\mathrm{x})(\cdot)(\mathrm{is})=\overline{\mathrm{LF}_{+} \mathrm{u}(\mathrm{x})(\cdot)(\mathrm{is})} \\
& \operatorname{Imu}(\mathrm{s}) \equiv 0, \mathrm{~s} \in(-\infty, \infty)
\end{aligned}
$$

Equality, we obtain:

$$
\begin{aligned}
& \operatorname{ImL}(\mathrm{s})=-\operatorname{Iml}(\mathrm{s}) \\
& 1(\mathrm{~s})=\mathrm{LF}_{+} \mathrm{u}(\mathrm{x})(\cdot)(\mathrm{is}), \mathrm{s} \in(-\infty, \infty)
\end{aligned}
$$

Pavlov (2011, 2014a, b, 2017). We will prove that similar equality takes place with sign plus. We can consider the fractionally-linear represent (Lavrentiev and Shabat, 1987):

If:

$$
\mathrm{p}=\mathrm{s}=\mathrm{ih}(\mathrm{az}+\mathrm{d}) /(\mathrm{bz}+\mathrm{c})=\mathrm{f}(\mathrm{z})
$$

$$
\mathrm{a}=1, \mathrm{~b}=-1, \mathrm{~d}=\mathrm{c}=\mathrm{e}^{\mathrm{i} \alpha}, \alpha, \mathrm{h} \in(0,+\infty)
$$

The $f(z)$ function represents:

$$
\{\mathrm{z}:|\mathrm{z}| \leq 1\}=\mathrm{S} \rightarrow \mathrm{G}_{+}
$$

Where:

$$
\mathrm{G}_{+}=\{\mathrm{p}: \operatorname{Imp} \geq 0\}
$$

Lavrentiev and Shabat (1987) such that the:

$$
\mathrm{C}_{1}=\{\mathrm{W}:|\mathrm{w}|=1\}
$$

circle passes to the line:

$$
\begin{gathered}
\mathrm{C}_{1} \rightarrow(-\infty, \infty) \\
\mathrm{f}(\mathrm{w})=\mathrm{s}, \mathrm{s} \in(-\infty, \infty),|\mathrm{w}|=1
\end{gathered}
$$

We obtain:

$$
\mathrm{L}(\mathrm{f}(\mathrm{w}))=\mathrm{L}(\mathrm{s})
$$

for all:

$$
|\mathrm{w}|=1, \mathrm{~s} \in(-\infty, \infty)
$$

From the definition of the:

$$
1(p)=L_{+} u(x)(\cdot)(i p), \operatorname{Imp} \leq 0
$$

function (for the same $\mathrm{f}(\mathrm{z})$ function), we obtain the new:

$$
1(\mathrm{f}(\mathrm{z}))
$$

function from $\mathrm{S}$ to:

$$
\mathrm{G}_{-}=\{\mathrm{p}: \operatorname{Imp} \leq 0\}
$$

such that:

$$
\mathrm{S} \rightarrow \mathrm{G}_{-}, \mathrm{C}_{1} \rightarrow(-\infty, \infty)
$$

We will mark that the real part of the new $1(f(z))$ function on the $|z|=1$ is the same as the real part of the old $\mathrm{L}(\mathrm{f}(\mathrm{z}))$ function on the same set:

$$
\operatorname{ReL}(f(z))=\operatorname{Re}((f(z)),|z|=1
$$

with help of the equality:

$$
\begin{aligned}
& \operatorname{ReL}(\mathrm{s})=\operatorname{Rel}(\mathrm{s}), \mathrm{s} \in(-\infty, \infty) \\
& \mathrm{s}=\mathrm{f}(\mathrm{w}),|\mathrm{w}|=1
\end{aligned}
$$

From the decision of the Dirichlet problem in:

$$
|z| \leq 1
$$

the complex parts of the:

$L(f(z)), 1(f(z))$ 
functions (the two integrals by Schwartz, Lavrentiev and Shabat (1987) are the same:

$$
\operatorname{ImL}(\mathrm{f}(\mathrm{z}))=\operatorname{Iml}(\mathrm{f}(\mathrm{z}))+\mathrm{c},|\mathrm{z}|=1
$$

without the minus:

$$
\begin{aligned}
& \operatorname{ImL}(\mathrm{s})=\operatorname{ImL}(\mathrm{f}(\mathrm{z}))=\operatorname{Iml}(\mathrm{f}(\mathrm{z}))=\operatorname{Iml}(\mathrm{s}) \\
& \mathrm{f}(\mathrm{z})=\mathrm{s} \in(-\infty, \infty),|\mathrm{z}|=1
\end{aligned}
$$

it is obvious, $\mathrm{c}=0$ from:

$$
\mathrm{L}(\mathrm{s}) \rightarrow 0, \mathrm{~s} \rightarrow \pm \infty
$$

in the $\mathrm{Y} 1$ conditions. We use that both:

$$
\mathrm{L}(\mathrm{f}(\mathrm{z})), 1(\mathrm{f}(\mathrm{z}))
$$

functions are regular in:

\section{$|z| \leq 1$}

the functions are continuous on the $|z|=1$ from the $|z|<1$ side and:

$$
\begin{aligned}
& \mathrm{L}\left(\mathrm{p}_{1}\right) \rightarrow 0, \mathrm{p}_{1} \rightarrow \infty \bigcap \operatorname{Re} \mathrm{p}_{1} \leq 0 \\
& 1\left(\mathrm{p}_{1}\right) \rightarrow 0, \mathrm{p}_{1} \rightarrow \infty \bigcap \operatorname{Re} \mathrm{p}_{1} \geq 0
\end{aligned}
$$

Pavlov-Maxorin (2018), Pavlov (2013, 2014a, b) (the definition of the $f(z)$ function by Lavrentiev and Shabat (1987) too). The:

$$
\mathrm{L}\left(\mathrm{p}_{1}\right) \rightarrow 0,1\left(\mathrm{p}_{1}\right) \rightarrow 0, \mathrm{z} \rightarrow \mathrm{c}=\mathrm{e}^{\mathrm{i} \alpha}
$$

Equalities, we obtain from:

$$
\begin{aligned}
& 1\left(\mathrm{p}_{1}\right)=\mathrm{C}(0) / \mathrm{p}_{1}+ \\
& \left(\mathrm{i} / \mathrm{p}_{1}\right) \mathrm{LF}_{+} \mathrm{xu}(\mathrm{x})(\cdot)\left(\mathrm{p}_{1}\right) \rightarrow 0, \mathrm{p}_{1} \rightarrow \infty \\
& \operatorname{Rep}_{1} \geq 0, \mathrm{C}(0)=\text { const., } \mathrm{C}(0)<\infty
\end{aligned}
$$

and from:

$$
\begin{aligned}
& \left|F_{+} x u(x)(\cdot)(t)\right|= \\
& \left|\left(1 / t^{2}\right) F_{+}\left(d^{2}(x u(x)) / d x^{2}\right)(\cdot)(t)\right| \leq c_{1} / t^{2} \\
& t \rightarrow \pm \infty
\end{aligned}
$$

with help of the formula of the integration by parts (Fichtenholz, 1969) (we use the Y1 condition for the $u(x)$ function too). From:

$$
\begin{gathered}
\operatorname{ImL}(\mathrm{s})=\operatorname{Iml}(\mathrm{s}) \\
\operatorname{ImL}(\mathrm{s})=-\operatorname{Iml}(\mathrm{s}), \mathrm{s} \in(-\infty, \infty)
\end{gathered}
$$

we obtain:

$$
\operatorname{Im} L(s)=0, s \in(-\infty, \infty)
$$

The theorem 1 is proved.

Remark 1: From the researches of Pavlov-Maxorin (2018), Pavlov (2017), Pavlov (2014), Kolmogorov and Fomin (1976), Lavrentiev and Shabat (1987) and Pavlov (2013) with help of the theorem 1, we get the equality (about the potential):

$$
\begin{aligned}
& \mathrm{C}^{0} \mathrm{~S}^{0} \mathrm{u}(\mathrm{x})\left(\cdot(\mathrm{s})-\mathrm{S}^{0} \mathrm{C}^{0} \mathrm{u}(\mathrm{x})(\cdot)(\mathrm{s})=\right. \\
& \operatorname{ImLF} \mathrm{u}(\mathrm{x})(\cdot)(\mathrm{is})= \\
& \int_{0}^{\infty} \frac{\mathrm{u}(\mathrm{r})}{\mathrm{s}-\mathrm{r}} \mathrm{dr} \equiv 0, \mathrm{~s} \in[0, \infty)
\end{aligned}
$$

From the theorem 1 with help of the inverse transform of Fourier (Kolmogorov and Fomin, 1976), we obtain the remark 2 .

\section{Remark 2:}

$$
\begin{aligned}
& 0=\operatorname{ImLF}_{+}\left[\mathrm{C}^{0} \mathrm{u}(\mathrm{t})(\cdot)(\mathrm{x})+\mathrm{S}^{0} \mathrm{u}(\mathrm{t})(\cdot)(\mathrm{x})\right](\text { is })= \\
& \pi\left[\mathrm{C}^{0} \mathrm{u}(\mathrm{t})(\cdot)(|\mathrm{s}|)+\mathrm{S}^{0} \mathrm{u}(\mathrm{t})(\cdot)(|\mathrm{s}|)\right] \mathrm{s} \in(-\infty, 0)
\end{aligned}
$$

and:

$$
\mathrm{C}^{0} \mathrm{u}(\mathrm{t})(\cdot)(\mathrm{x})=-\mathrm{S}^{0} \mathrm{u}(\mathrm{t})(\cdot)(\mathrm{x}), \mathrm{x} \in[0,+\infty)
$$

if for the $u(x)$ function the $Y 1$ condition takes place (Pavlov-Maxorin, 2018; Pavlov, 2017):

Proof: We can use the inverse equation of the transform of Fourier (Kolmogorov and Fomin, 1976) with help of:

$$
\begin{gathered}
\max \left[\left|\mathrm{C}^{0} \mathrm{t}^{\mathrm{k}} \mathrm{u}(\mathrm{t})(\cdot)(\mathrm{x})\right|,\left|\mathrm{S}^{0} \mathrm{t}^{\mathrm{k}} \mathrm{u}(\mathrm{t})(\cdot)(\mathrm{x})\right|\right] \leq \\
\mathrm{c} / \mathrm{x}^{1+\delta}, \mathrm{c}<\infty, \mathrm{x} \rightarrow+\infty \\
\text { if } \mathrm{u}(0)=0, \mathrm{c}=\text { const., } \mathrm{k}=0,1,2 .
\end{gathered}
$$

\section{CONCLUSION}

From point of physical applications the sine and cosine transform of Fourier are the components of electromagnetic fields (or can be considered as the components). It is of interest to find the physical applications with the identical components in that or other sense. In the inlying integral of the:

$$
\mathrm{LS}_{+}^{0} \mathrm{u}(\mathrm{x})(\cdot)(\mathrm{is})
$$


Expression after integration on parts appears the $u(0) / t$ element if $u(0 \neq 0)$ in opinion of researcher the fact can result in description of some physical phenomena in connection with research of the integral from $\mathrm{e}^{\mathrm{its}} \mathrm{u}(0) / \mathrm{t}$.

\section{REFERENCES}

Fichtenholz, G.M., 1969. Course of Differential and Integral Calculus. Vol. 2, Moscow Science Publisher, Moscow, Russia, Pages: 800.

Kolmogorov, A.N. and S.V. Fomin, 1976. [Elements of the Theory of Functions and Functional Analysis]. USSR Academy of Sciences Publishing House, Moscow, Russia, Pages: 544 (In Russian).

Lavrentiev, M.A. and B.V. Shabat, 1987. [Methods of the Theory of Functions of a Complex Variable]. URSS Science Publisher, Moscow, Russia, Pages: 688 (In Russian).

Pavlov, A., 2014b. The new inversion of Laplace transform. J. Math. Syst. Sci., 4: 197-201.

Pavlov, A.V., 2011. The Fourier transform and the formula of Laplace transforms. Math. Notes, 90: $792-796$.
Pavlov, A.V., 2013. Disciplines with Priority Short Requirements and Identical Services. FGBOU VO Publisher, Moscow, Russia, ISBN:978-5-7339-1261-5, Pages: 119.

Pavlov, A.V., 2014a. Reliable prognosis of the functions in the form of transformations of Fourier or Laplace: Herald of MIREA, Moscow Institute of Rad. Electron. Autom., 3: 78-85.

Pavlov, A.V., 2016. About the equality of the transform of Laplace to the transform of Fourier. Prob. Anal., 5: 21-30.

Pavlov, A.V., 2017. The Dirichle't problem and disappearance of the imaginary part of the Laplace transform on the imaginary axis in connection with the Fourier-Laplace operators. Proceedings of the 8th International Conference on Differential and Functional Differential Equations, August 13-20, 2017, Peoples Friendship University of Russia, Moscow, Russia, pp: 137-138.

Pavlov-Maxorin, V.A., 2018. About equality of the cosine transform to the sine transform of Fourier. J. Transf. Eng. Sci., 1: 1-6. 